\title{
1 Incommensurateness Is Vagueness
}

\author{
John Broome
}

\section{Introduction}

When we have to make a decision, it often seems indeterminate what would be the best thing to do. ${ }^{1}$ The alternatives seem "incommensurate" with each other, to use the term I favor. ("Incommensurable," "incomparable," "on a par," and other terms are often used instead.) The classic example is the choice faced by a student of Jean-Paul Sartre's in wartime France (Sartre, 2007). The student could choose to stay at home to look after his mother, who badly needed him, or he could try to escape to Britain and join the Free French Forces. Sartre took these alternatives to be incommensurate with each other. The aim of this chapter is to try to persuade you that incommensurateness like this is nothing more than vagueness.

We are interested in what is the best thing for the student to do, which is a matter of comparative value. In other words, it is a matter of betterness: what is better than what? Betterness is a comparative relation. When a monadic property $F$ comes in degrees, it has a comparative more $F$ than or Fer than, which is a dyadic relation. Betterness is the comparative of the monadic property of goodness.

Among comparative relations, betterness is especially important because of its connection with normativity - with what we ought to do. This chapter concentrates on it for this reason. However, betterness shares the common features of comparatives in general. Many other comparatives exhibit incommensurateness, for example. The analysis of incommensurateness is therefore not in itself particularly a topic within the philosophy of value; it is a topic concerned with the structure of comparatives in general. We can ask in general whether incommensurateness is vagueness.

That is where this chapter starts. The next three sections examine incommensurateness in general. Section 2 explains that there are two alternative sorts of it, which I call soft and hard incommensurateness, respectively. Soft incommensurateness is simply vagueness; hard incommensurateness is something else. 


\section{John Broome}

In Sections 3 and 4, I shall describe two formal considerations that argue in favor of soft incommensurateness, though not conclusively.

Then in Section 5, I turn to incommensurateness of betterness specifically. This is a particular bone of contention because of the connection between betterness and normativity. I describe a well-known normative puzzle that arises from the incommensurateness of betterness.

The rest of the chapter examines solutions to this puzzle. Sections 6, 7 , and 8 describe solutions that can be provided on the basis of hard incommensurateness. Section 1.9 describes a solution that can be provided on the basis of soft incommensurateness. It argues that this solution is the best.

\section{Hard and Soft Incommensurateness}

I say two things are incommensurate in respect of a comparative Fer than when neither is definitely Fer than the other and also they are not definitely equally $\mathrm{F}$.

As an example, I shall use the comparative relation redder than, which I call "redderness." Redderness is the comparative of the monadic property of redness. Figure 1.1 illustrates a part of the redderness relation as it holds among colors. Sadly, I have not been offered color printing in this volume, so I have to ask you to use your imagination. To keep things simple, I hold one color constant and examine how other colors are related to this one. My constant is the color A in the diagram, which is a reddish orange. I compare this with the range of colors $\mathrm{B}$, which extend from pure red at the top to bluish purple at the bottom. Figure 1.1 indicates which colors in this range are redder than A.

The colors toward the top are definitely redder than A, and the colors toward the bottom are definitely not redder than A. In the middle are

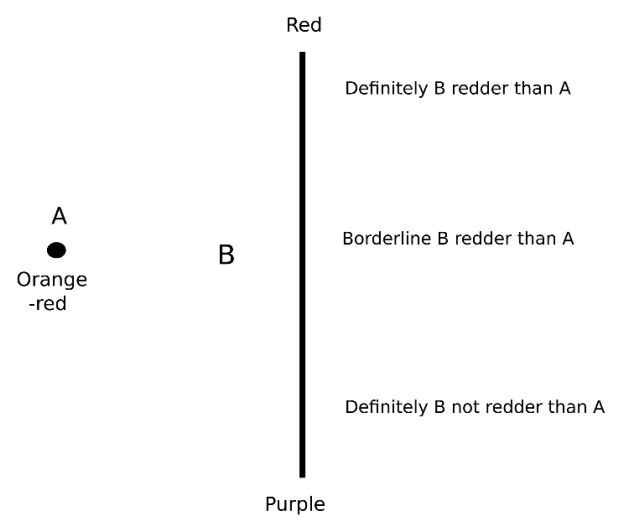

Figure 1.1 Colors redder than A. 
colors that lie on the borderline between being redder than $\mathrm{A}$ and not being redder than $\mathrm{A}$. The property of being redder than $\mathrm{A}$ is a monadic property and it is plainly vague. Some colors definitely possess it, and others definitely do not. In between are borderline colors, as the figure shows.

The vagueness of redderness is a sort of incommensurateness. Borderline colors are not definitely redder than A, nor definitely not redder than A, nor definitely equally as red as A. I call this "soft incommensurateness."

In this chapter, when I need an analysis of vagueness, I shall assume supervaluation (Fine, 1975). According to supervaluation, a vague property is a package of sharp properties called its "sharpenings." A proposition involving a vague property can be sharpened by replacing the vague property with one of its sharpenings. The original proposition is definitely true if and only if every one of its sharpenings is true.

In Figure 1.1, each color within the range B, if it is in the borderline between colors that are definitely redder than A and those that are definitely not redder than A, can represent a particular sharpening of the redderness relation. According to this sharpening, any higher color is redder than A and any lower color is not redder than A. By the same token, a color in the borderline also represents a sharpening of the monadic property redder than A. Any color that lies above the borderline is, therefore, redder than A according to every sharpening, so it is definitely redder than A. Correspondingly, any color that lies below the borderline is definitely not redder than $\mathrm{A}$.

Figure 1.1 illustrates a part of the redderness relation, and Figure 1.2 illustrates a different part of it. The same constant color A is compared with the same range $\mathrm{B}$, but the comparison is reversed. This diagram identifies which colors A is redder than. A is definitely redder than colors toward the bottom of the range. It is definitely not redder than colors toward the top of the range. In between are borderline colors.

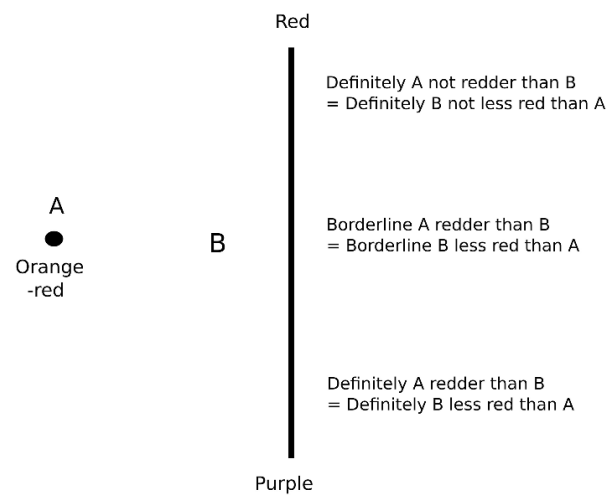

Figure 1.2 Colors A is redder than. 


\section{John Broome}

Any color within this borderline represents a sharpening of the redderness relation, but this time a different sharpening. It also represents a sharpening of the monadic property less red than $A$. ("B is less red than A" means the same as " $\mathrm{A}$ is redder than B", and I shall swap freely between the two expressions.) According to this sharpening, $\mathrm{A}$ is redder than any lower color, and $\mathrm{A}$ is not redder than any higher color. Or - to put it another way - any lower color is less red than A and any higher color is not less red than A. A is therefore definitely redder than any color that lies below the borderline and definitely not redder than any color that lies above it.

So comparing $A$ with the range $B$ in terms of their redderness reveals two borderlines. How do the two align with each other? One possibility is that they are the same: the colors on the borderline between being redder than $\mathrm{A}$ and not being redder than $\mathrm{A}$ are also on the borderline between being less red than A and not being less red than A. Figure 1.3 shows this possibility. I call it "matching vagueness."

A second possibility is that the borderlines overlap but are not the same. Figure 1.4 shows this possibility. I call it "overlapping vagueness."

A third is that the borderlines do not overlap at all. Figure 1.5 shows this possibility. The lack of overlap introduces a new feature. Some of the colors around the middle of the range $\mathrm{B}$ are definitely not redder than $\mathrm{A}$, and also $\mathrm{A}$ is definitely not redder than them. An example is $\mathrm{B}_{1}$. $\mathrm{A}$ is definitely not redder than $\mathrm{B}_{1}, \mathrm{~B}_{1}$ is definitely not redder than $\mathrm{A}$, and $\mathrm{A}$ and $\mathrm{B}_{1}$ are definitely not equally red.

I say there is "hard incommensurateness" between two things with respect to a comparative Fer than when definitely neither is Fer than the other and definitely they are not equally F. So there is hard incommensurateness between $A$ and $B_{1}$ with respect to redderness.

Hard incommensurateness is not vagueness. The topic of this chapter is in effect whether the betterness relation has hard incommensurateness. I

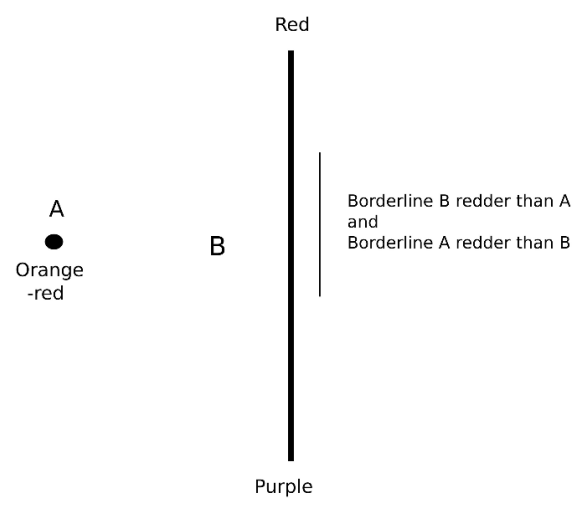

Figure 1.3 Matching vagueness. 


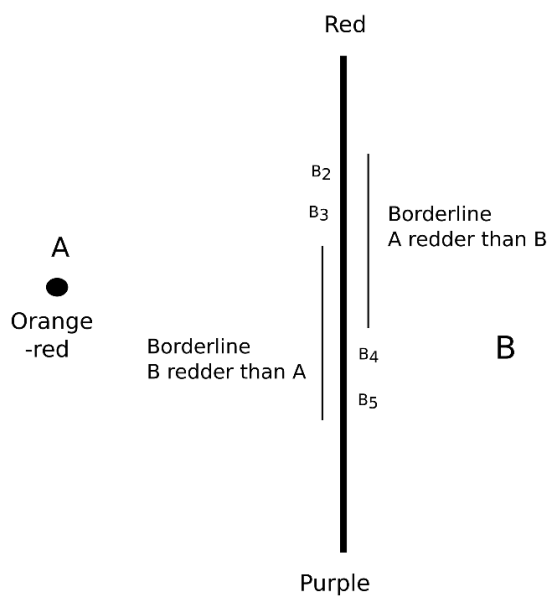

Figure 1.4 Overlapping vagueness.

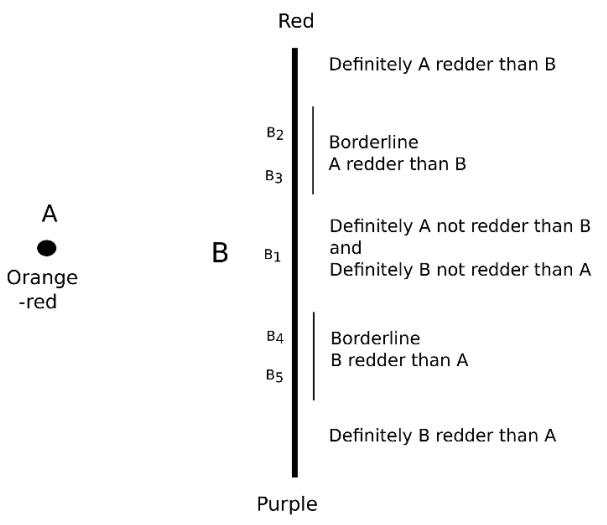

Figure 1.5 Non-overlapping vagueness.

shall argue that it does not. This implies that all the incommensurateness in betterness is vagueness.

How can the question be settled? It may be that some comparatives have hard incommensurateness and others do not. There are some formal considerations to take into account that apply to all comparatives. I shall mention two. Neither of them is conclusive, but they constitute a prima facie case against hard incommensurateness in general.

\section{The Collapsing Principle}

The first consideration is this. If you look at the color $\mathrm{B}_{2}$ in Figure 1.4 or Figure 1.5, you will see something puzzling about it. A is definitely not redder than $\mathrm{B}_{2}$. On the other hand, it is borderline whether or not $\mathrm{B}_{2}$ 


\section{John Broome}

is redder than $\mathrm{A}$. So the status of $\mathrm{B}_{2}$ 's redness in comparison to $\mathrm{A}$ is not symmetrical: $B_{2}$ is better off than $A$ with regard to redness. It is therefore puzzling why it is not definitely redder than A. You would think that possessing a higher status with regard to redness would be enough to make $\mathrm{B}_{2}$ definitely redder. Yet according to those diagrams, this is not so.

This casts suspicion on the configurations shown in those two diagrams. This suspicion attaches to the formal configuration and has nothing to do with the particular example of redderness. It suggests that hard incommensurateness may not exist at all.

I once formulated this suspicion as something I called "the collapsing principle" (Broome, 1998). It may be expressed this way:

If $\mathrm{X}$ is definitely not Fer than $\mathrm{Y}$ but $\mathrm{Y}$ is not definitely not Fer than $\mathrm{X}$, then $\mathrm{Y}$ is definitely Fer than $\mathrm{X}$.

I have now been convinced that the collapsing principle is not true in every case. Luke Elson has developed some convincing counterexamples to it. ${ }^{2}$

Here is one of them. Elson tells us that, when he plans a holiday, he prefers to visit a large country. It is not that he prefers one country to another if and only if it is larger. Among large countries, he has no preference on grounds of largeness, nor does he among countries that are not large. But he prefers any large country to any country that is not large. The relation that constitutes the counterexample is better than as a holiday destination for Elson, which I shall write as just better than. It is the comparative of the monadic property good as a holiday destination for Elson or good. A country is definitely good if and only if it is definitely large.

Elson tells us that China is definitely large, Ireland is definitely not large, and France is borderline large. Consequently, Ireland is definitely not better than France, but France is not definitely not better than Ireland. By the collapsing principle, therefore, France is definitely better than Ireland. On grounds I shall explain next, Elson argues that this can be so only if France is definitely good, which is to say definitely large.

By parallel reasoning, comparing France with China, we may also conclude that France is definitely not large, which implies it is not definitely large. The collapsing principle therefore implies a contradiction, so it is false. That is Elson's conclusion.

How does Elson derive "France is definitely good" from "France is definitely better than Ireland" ?3 We cannot, in general, derive " $\mathrm{X}$ is definitely F" from "X is definitely Fer than Y." For example, we cannot derive "Andorra is definitely large" from "Andorra is definitely larger than Monaco". So we need an argument.

The derivation is valid for sharp monadic properties. We can validly derive " 5 is prime" from " 5 is more prime than 4 ." But Elson is not interested in sharp properties because the collapsing principle is trivially true 
of them. A sharp monadic property $\mathrm{F}$ has a sharp comparative Fer than. This means that when $\mathrm{X}$ is not definitely not Fer than $\mathrm{Y}$ it is automatically definitely Fer than Y.

Elson needs his monadic property to be vague, and indeed good is vague. France is borderline good because it is borderline large. But the collapsing principle implies France is definitely better than Ireland, and Elson claims this is inconsistent with France's being only borderline good. It has to be definitely good.

This can be demonstrated by supervaluation applied to the monadic property goodness. Every sharpening of goodness identifies a particular size as the boundary between countries that are good and those that are not good. According to any sharpening, all the good countries are equally as good as each other, and all the not good countries are also equally as good as each other. That is the way goodness as a holiday destination for Elson works.

Now suppose France was only borderline good. Then there would be at least one sharpening of goodness in which France is not good. But in this sharpening, France would be equally as good as Ireland, which is also not good. Consequently, in this sharpening, France would not be better than Ireland. Since there would be at least one sharpening in which France is not better than Ireland, France would not be definitely better than Ireland as the collapsing principle implies. So the collapsing principle implies that France is definitely good.

I think Elson's is a sound counterexample to the collapsing principle. However, it works only because of an exceptional feature of the property in question. Both the monadic property of goodness and its comparative betterness are vague. Each has a number of sharpenings. The special feature is that in every sharpening of both, no country that is not good is better than any other country that is not good. Elson's highly contrived property is designed to have this feature. I know of no more natural properties that do.

Moreover, although Elson's is a counterexample to the collapsing principle, it is not an example of hard incommensurateness. True, the borderlines of the two vague properties better than France and worse than France do not overlap. But between them lie only countries that are the same size as France, and these are all definitely equally as good as France. Any countries that are definitely not better than France and definitely not worse than France are definitely equally as good as France.

Erik Carlson (2013) and subsequently Andersson and Herlitz (2018) have pointed out that this weaker version of the collapsing principle is immune to Elson's example:

If $\mathrm{X}$ is definitely not Fer than $\mathrm{Y}$ but $\mathrm{Y}$ is not definitely not Fer than $\mathrm{X}$, then $\mathrm{Y}$ is definitely either Fer than $\mathrm{X}$ or equally as good as $\mathrm{X}$. 
Furthermore, these authors show that this weak principle, like the stronger version, implies there is no hard incommensurateness. But I see no independent attraction in it. If the collapsing principle itself is refuted, there are no grounds for clinging on to this weak version of it. ${ }^{4}$

I conclude that Elson has shown that the collapsing principle is not universally true. Moreover, other counterexamples have been described in the literature (e. g. Carlson, 2004 and Gustafsson, 2018). They are not as watertight as Elson's but are nevertheless effective. The collapsing principle is subject to severe doubt, therefore. But it remains intuitively attractive and may well be true for common cases. Where it is true, it implies that matching vagueness is the correct account of incommensurateness. So it provides some evidence in favor of matching vagueness. A fortiori, it provides some evidence against hard incommensurateness.

\section{Gradation}

I shall say no more about the collapsing principle. This chapter concentrates on the second formal consideration that opposes hard incommensurateness. It is this. Intuitively, incommensurateness has a graded structure. As we move through the range B from bottom to top, we move from colors that are definitely less red than A to ones that are definitely redder than A. In between is a zone of colors that are neither. In moving up through this incommensurate zone, we of course come to colors that are progressively redder. Intuitively, it is also true that their comparative redderness in comparison to A progressively increases. It is easy to make sense of this intuition of gradation in terms of vagueness. But if there is hard incommensurateness, it is not so easy.

Vagueness supplies gradation through this principle:

Greatervaluation. $\mathrm{X}$ is Fer than $\mathrm{Y}$ if $\mathrm{X}$ is $\mathrm{F}$ according to every sharpening of $\mathrm{F}$ in which $\mathrm{Y}$ is $\mathrm{F}$, and $\mathrm{X}$ is $\mathrm{F}$ according to some sharpening of $\mathrm{F}$ in which $\mathrm{Y}$ is not $\mathrm{F}$.

In Broome (1998: 83), I offered greatervaluation as a general truth. However, Henrik Andersson and Ruth Chang have shown me it is not one. Whereas vagueness can induce gradation on a property through greatervaluation, many properties have a prior gradation on some different basis. For instance, there are degrees of redness even among colors that are definitely red, and this gradation cannot derive from the vagueness of red. For some properties, this prior grading on a different basis can override grading on the basis of vagueness. But I am now using greatervaluation only in order to explain how grading can be based on vagueness.

Let $\mathrm{F}$ be the property redder than $\mathrm{A}$. Take two colors $\mathrm{B}_{2}$ and $\mathrm{B}_{3}$ in the borderline of this property, where $\mathrm{B}_{2}$ is above $\mathrm{B}_{3}$. Each sharpening of red$\operatorname{der} \operatorname{than} A$ is represented by a color within the borderline. According to 
all sharpenings represented by colors below $\mathrm{B}_{3}$, both $\mathrm{B}_{2}$ and $\mathrm{B}_{3}$ are redder than $\mathrm{A}$. According to all sharpenings represented by colors between $\mathrm{B}_{3}$ and $B_{2}, B_{2}$ is redder than $A$, but $B_{3}$ is not. So by greatervaluation, $B_{2}$ is redder than $A$ more than $\mathrm{B}_{3}$ is redder than $\mathrm{A}$. This supports the intuition of gradation within this borderline.

Next, let $\mathrm{F}$ be the property less red than $A$. Take two colors $\mathrm{B}_{4}$ and $\mathrm{B}_{5}$ in the borderline of this property, where $\mathrm{B}_{4}$ is above $\mathrm{B}_{5}$. Each sharpening of less red than $A$ is represented by a color within the borderline. According to all sharpenings represented by a color above $\mathrm{B}_{4}$, both $\mathrm{B}_{4}$ and $\mathrm{B}_{5}$ are less red than $\mathrm{A}$. According to all sharpenings represented by colors between $\mathrm{B}_{4}$ and $\mathrm{B}_{5}, \mathrm{~B}_{5}$ is less red than $\mathrm{A}$, but $\mathrm{B}_{4}$ is not. So by greatervaluation, $\mathrm{B}_{5}$ is less red than $A$ more than $\mathrm{B}_{4}$ is less red than $\mathrm{A}$. This supports the intuition of gradation within this borderline.

So there is increasing redderness in the borderlines. But in the zone of hard incommensurateness in Figure 1.5, which lies between the two borderlines, redderness apparently does not increase as we move up through the zone. Any color in this zone is definitely not redder than A and definitely not less red than $\mathrm{A}$, and this is equally so for any color in the zone. Hard incommensurateness seems to create a hiatus in the gradation of redderness, between the zones of vagueness in which redderness is graded.

At least, in the zone of hard incommensurateness, no gradation results from greatervaluation. A gradation could be supplied by other means but demonstrating gradation would require more assumptions and more theoretical apparatus. This is further inconclusive evidence against hard incommensurateness.

\section{A Puzzle about Betterness}

I turn now from redderness to the more important topic of betterness. The example of Sartre's student is illustrated in Figure 1.6. The student has a choice between A, staying in France with his mother or B, leaving for Britain to join the Free French Forces. Is either better than the other? This depends on the details of each. For example, it depends on how likely it is that he will get to Britain if he tries and on how much his mother needs him. The question is illustrated in Figure 1.6. For the sake of analysis, I shall once again hold one of the options constant. For this role, I have chosen the option of staying in France, which I assume will be in the conditions described by Sartre. B is a range of different versions of the option of leaving. High up are cases where it is easy to get to Britain, and the student's contribution to liberating France is likely to be great. For these, I assume that leaving is definitely better than staying. Low down in the range are cases where travel is very dangerous, and he is likely not to succeed. Staying is definitely better than leaving in one of these cases. Since the considerations that favor either option are very different from each other, it is plausible that there is a range of cases in 


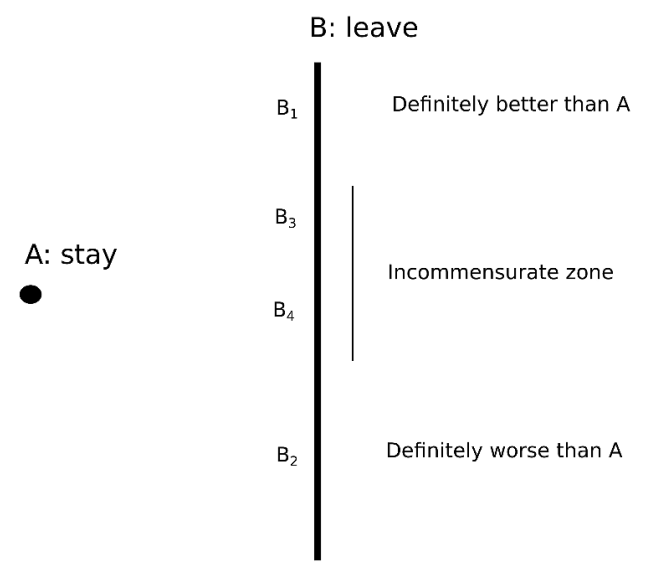

Figure 1.6 Sartre's student.

between where staying is not definitely better than leaving, and leaving is not definitely better than staying. These are incommensurate cases.

Betterness, like redderness, is undoubtedly vague. One possibility is that all the incommensurateness is soft, which is to say that it consists entirely of vagueness. In that case, the whole incommensurate zone consists of the borderlines of the properties better than $A$ and worse than $A$, which overlap to some extent. The two borderlines may even coincide exactly; this is the case of matching vagueness.

It is also possible that within the range of $\mathrm{B}$, there is a zone where the incommensurateness is hard. In a zone of hard incommensurateness, staying is definitely not better than leaving, and leaving is definitely not better than staying, and staying and leaving are definitely not equally good.

Which is the correct account of the situation? Is there hard incommensurateness or not? This is the same question for betterness as for any other comparative. The same formal considerations arise as the ones I described for redderness, stemming from the collapsing principle and from gradation. Both provide some evidence against hard incommensurateness.

The question assumes special importance for betterness because of the connection between betterness and normativity. This connection also provides a different perspective on the question, besides the formal considerations. We can ask what sort of incommensurateness provides the best account of normative phenomena that need explaining. Since, of course, betterness is vague, we automatically have soft incommensurateness as a resource for explaining the phenomena. We can ask whether we also need hard incommensurateness as a further resource.

I shall argue we do not. It has been recognized for a long time that incommensurateness throws up a particular normative puzzle (see Chang, 1998: 11). I shall argue that, not only do we not need hard incommensurateness 
to solve it, but soft incommensurateness provides a better solution to it than hard incommensurateness does. It will turn out in Section 9 that this is because of one of the formal considerations: a good solution requires betterness to be graded.

As a preliminary to describing the puzzle, I need to specify one small part of the connection between betterness and normativity. Betterness affects what you ought to do. In many cases, it does not fully determine what you ought to do, but in some cases it does. Take a case where it does and suppose that in such a case a person has a choice between just two options. Then she ought to choose one of them if and only if it is better than the other. This is a minimal assumption about the connection.

As I am going to use "permissible," it is permissible for you to choose an option if and only if it is not the case that you ought not to choose it. Given there are only two options, you ought not to choose one if and only if you ought to choose the other. So the minimal assumption implies that it is permissible for you to choose an option if and only if the other is not better than it.

Let us assume the example of the student is a case where betterness fully determines what you ought to do. To justify this assumption, we shall have to recognize a wide range of values, perhaps including national honor and the performance of filial duties. Let us recognize all the goods we need to and incorporate all of them into betterness. So, for instance, if the student has a choice between $A$ and $B_{1}$ in Figure 1.6, he ought to choose $\mathrm{B}_{1}$, and if he has a choice between $\mathrm{A}$ and $\mathrm{B}_{2}$, he ought to choose $\mathrm{A}$.

Now concentrate on two options $B_{3}$ and $B_{4}$ that are both incommensurate with $\mathrm{A}$. If there is a zone of hard incommensurateness, assume they are both in that zone. If there is no hard incommensurateness, they are both softly incommensurate with $\mathrm{A}$.

These two options can illustrate the normative puzzle I mentioned. Suppose the student is offered two choices on successive days. Today, he is offered a choice between A, staying in France, and $\mathrm{B}_{3}$, which is travel to Britain by a reasonably safe means. He chooses A. The next day he is offered a choice between $\mathrm{A}_{\text {and }} \mathrm{B}_{4}$. By then the safer means of travel has shut down, and $\mathrm{B}_{4}$ involves less safe travel. This time the student chooses $\mathrm{B}_{4}$. On the face of it, there seems to be nothing wrong with either of his two choices since he does not choose a worse option out of those he is offered. Yet he ends up with $\mathrm{B}_{4}$ when he could have had $\mathrm{B}_{3}$, and $\mathrm{B}_{4}$ is definitely worse than $B_{3}$. Had he been offered all three options at once, he definitely ought not to have chosen $\mathrm{B}_{4}$. This is the puzzle. If the student makes the choices I have described, does he do something impermissible, and if so, what? It seems he should have some normative protection against this bad outcome. What can it be?

What solution to this puzzle can be offered by different accounts of incommensurateness? 


\section{Hard Incommensurateness: The First Solution}

Let us first assume the incommensurateness is hard and see what follows. In that case, definitely, neither $\mathrm{A}_{\text {nor }} \mathrm{B}_{3}$ is better than the other. Suppose the student has a choice between these two options only. My minimal assumption about the connection between betterness and normativity implies it is definitely permissible for him to choose A and definitely permissible for him to choose $\mathrm{B}_{3}$. Similarly, in a choice between $\mathrm{A}_{\text {and }} \mathrm{B}_{4}$, it is definitely permissible for him to choose $\mathrm{A}$ and definitely permissible for him to choose $\mathrm{B}_{4}$. So both the choices he makes are definitely permissible, yet a bad outcome results. That is the puzzle.

Various solutions are available given the assumption of hard incommensurateness. A solution I once offered myself (Broome, 2001) is to say that actually, the student does nothing wrong. There is no normative protection against the bad result. However, causal processes may well protect him from it. When he chooses A on the first day, he forms an intention to stay with his mother. A person's intentions typically persist until they are fulfilled, and they typically cause the person to take means toward their fulfillment. On the second day, the student can be expected still to have the intention he formed on the first day. A means toward its fulfillment is to reject the option $\mathrm{B}_{4}$. If he does that, he avoids the bad outcome. It is prevented just by the causal tendency of intentions to persist. Sadly, this protection against the bad outcome is weak because the student might easily change his mind on the second day and give up his intention.

More recently (Broome, 2013: Section 10.1) I came to think that the causal tendency for an intention to persist has some rational support. It is not just that intentions typically do persist; under certain conditions, rationality requires them to persist. Among the conditions is that the person does not reconsider the intention. I claim it is not rational just to give up an intention you have without at least thinking about it. If the student thoughtlessly accepts the offer of $B_{4}$ on the second day, that would be irrational. He would go wrong at that point. Nevertheless, if he does think about it, it would not be irrational for him to accept the offer of $\mathrm{B}_{4}$ since it is a permissible choice for him to make. So, even reinforced with this rational support, causal protection against the bad outcome is weak.

The bottom line is that the student may do nothing wrong even though he comes to a bad outcome.

\section{Hard Incommensurateness: The Second Solution}

A second solution can be developed from an idea of Ruth Chang's (2017, 2021). I do not believe Chang herself has explicitly offered this idea as a solution to this particular puzzle, but it is easily turned to that purpose. Chang thinks that a person can create reasons for herself by making commitments. For example, the student might commit himself to his mother, 
and this commitment gives him a new reason to stay and look after her. Chang deals in reasons, but the point can be made for values too. A person can create values for herself by making commitments. For example, by committing himself to his mother, the student can make looking after her a particular value for him.

Moreover, Chang thinks that a "hard choice," such as the one the student makes, creates a special opportunity for making a commitment of this sort. When considering his choice on the first day, wondering whether to stay at home or leave for Britain, the student might decide to commit himself to his mother. If so, this makes the option of staying at home more valuable to him than it previously was. Whereas the option A of staying at home was previously not definitely better than $\mathrm{B}_{3}$, leaving for Britain, it may now become so. If it does, $\mathrm{A}$ is then also definitely better than $\mathrm{B}_{4}$. The value created by the commitment has consequences that extend beyond the particular choice where it was made. The student ought now to choose $\mathrm{A}$ on the second day too. If he chooses $\mathrm{B}_{4}$, he goes wrong. That is a solution to the puzzle.

However, it is only a partial solution because, whatever values a person creates by making commitments, she may still face an incommensurate choice. Self-made values have to be weighed against each other and against other values, and they may easily be incommensurate with them. It would take a total commitment to a single value to make this impossible, and that would at best provide a very rare and extreme solution to the puzzle. So now I want you to read the student example as having already taken into account all the student's self-made values, including all those he makes when considering his first choice. Assume that these commitments leave the student with a choice between incommensurate options, as we have been assuming up to now. In this case, we still have a puzzle. The commitments do not solve it.

Chang recognizes this possibility. She recognizes that a person faced with a "hard choice," as she calls it, may not settle the choice by making a commitment. Instead, she may drift into a decision (Chang, 2017: 18-19). I take Chang's word "drifting" to mean making the choice in some way that does not involve a commitment that projects a value beyond the particular choice. In choosing $\mathrm{A}_{\text {over }} \mathrm{B}_{3}$ on the first day, the student is not necessarily making a commitment. So it does not follow that, on the second day, he ought not to choose $\mathrm{B}_{4}$ over $\mathrm{A}$. The student may do nothing wrong at all.

We could deny that drifting is possible. We could claim that a person could not make a decision - or perhaps could not rationally make a decision - between two incommensurate options without making them commensurate by means of a commitment. But that would be entirely implausible. In order to make a rational choice between two options, you do not have to think one of them is better than the other. If you happen not to think so, rationality does not paralyze you. Buridan's ass was 


\section{2}

paralyzed in such a case and died as a result, but that was a failure of its rationality rather than a consequence of it. True, rationality requires you to choose to do whatever you believe you ought to do. But it does not require you not to choose to do anything that you do not believe you ought to do. Chang is right not to make this claim.

Another idea is that the decision between options itself creates a value so that any decision between options is itself a commitment of Chang's sort. But that is false, and Chang (2013) rejects it. She thinks that you can in effect decide you ought to do a particular act by making a commitment. Nevertheless, she recognizes that deciding to do something and deciding you ought to do it are different acts.

The bottom line is that the student may do nothing wrong, even though he arrives at a bad outcome.

\section{Hard Incommensurateness: The Third Solution}

Wlodek Rabinowicz (2012: 145) has a different way of solving the puzzle. He deploys a version of the fitting attitude account of value. This is a metaphysical theory about the nature of goodness. For something to be good is for it to be fitting to have a positive attitude toward it. Rabinowicz extends this account to betterness by saying that for one thing to be better than another is for it to be fitting to prefer the first to the second.

When neither of two things is better than the other and nor are they equally good, in typical cases Rabinowicz thinks it permissible to prefer one to the other and permissible to prefer the other to the one. He would think it permissible for the student to prefer $\mathrm{A}_{\text {to }} \mathrm{B}_{3}$ and permissible for him to have the opposite preference, and also permissible for the student to prefer $\mathrm{A}$ to $\mathrm{B}_{4}$ and permissible for him to have the opposite preference. But he must prefer $B_{3}$ to $B_{4}$ since $B_{3}$ is better. So it is not permissible for the student to prefer $A$ to $B_{3}$ and also prefer $B_{4}$ to $A$, even though both these preferences are individually permissible. This is because a permissible preference relation must not be cyclic, and these two preferences would form a cycle with the student's preference for $\mathrm{B}_{3}$ over $\mathrm{B}_{4}$.

Let us assume the student should make choices in accordance with his preferences. So if he chooses $A$ rather than $B_{3}$ and also $B_{4}$ rather than $A$, he does something impermissible. Either he does not choose in accordance with his preferences, or he prefers $A$ to $B_{3}$ and also prefers $B_{4}$ to $A$, which is impermissible. Rabinowicz's solution to the puzzle is to say that the student does indeed go wrong, and this is where.

This solution depends on assuming that permissible preferences must not be cyclic. Why should that be? Various answers are available, but none yields a very satisfactory solution to the solution to the puzzle.

One is to make a normative connection between permissible preferences and betterness. Since betterness is acyclic, we might be able to derive 
the conclusion that permissible preferences are acyclic. This answer does not suit Rabinowicz because he defines betterness in terms of permissible preferences, which he takes to be metaphysically prior to betterness. For him, if betterness is acyclic, that would have to be because permissible preferences are acyclic, rather than the other way around.

In any case, this answer does not help with the puzzle of the student. We might make the connection between permissible preference and betterness in either of two ways but neither succeeds. We might say it is permissible to prefer $\mathrm{X}$ to $\mathrm{Y}$ if and only if $\mathrm{X}$ is better than $\mathrm{Y}$. Then indeed permissible preferences will be acyclic. But we are assuming that $B_{3}$ is neither better nor worse than $\mathrm{A}$, so it will be impermissible for the student to prefer $\mathrm{B}_{3}$ to $\mathrm{A}$ and impermissible for him to prefer $\mathrm{A}$ to $\mathrm{B}_{3}$. Likewise, it will be impermissible for the student to prefer $\mathrm{B}_{4}$ to $\mathrm{A}$ and impermissible for him to prefer $\mathrm{A}_{\text {to }} \mathrm{B}_{4}$. Since he has to make choices, they cannot be constrained by his preferences, so we cannot use preferences to explain where he goes wrong.

Alternatively, we might say it is permissible to prefer $\mathrm{X}$ to $\mathrm{Y}$ unless $\mathrm{Y}$ is better than $\mathrm{X}$, and then it is impermissible to prefer $\mathrm{X}$ to $\mathrm{Y}$. But then permissible preferences may be cyclic. It is permissible for the student to prefer $A$ to $B_{3}, B_{4}$ to $A$, and $B_{3}$ to $B_{4}$. So this first explanation of acyclicity leaves the puzzle unanswered.

A second explanation is the "money-pump" argument. Rabinowicz subscribes to this argument. It has been much debated, and Rabinowicz's own version of it is designed to overcome objections that have been raised against it (Gustafsson \& Rabinowicz, 2020). But here I shall not question the validity of the argument; I am concerned only with its broad structure, so I shall describe only a simple version of it. Suppose you make choices in accordance with your preferences, and your preferences are cyclic. Suppose you prefer $\mathrm{Y}$ to $\mathrm{X}, \mathrm{Z}$ to $\mathrm{Y}$, and $\mathrm{X}$ to $\mathrm{Z}$. Imagine you start off with $X$ and are then offered the chance of swapping from X to Y. Because you prefer $Y$ to $X$, you accept this offer and take $Y$. Next suppose you are offered the chance of swapping from $Y$ to $Z$. You accept this offer too and end up with Z. But you prefer X, where you started, to $Z$, where you ended up. So you have arrived at a bad outcome. A course of action that leads to this outcome cannot be entirely permissible. It is presumably permissible to make choices in accordance with your preferences. So it must be your cyclic preferences that are not permissible.

This argument rests on the bad outcome of getting $\mathrm{Z}$ when you could have had X. This is just the sort of bad outcome that Sartre's student comes to in my version of his story. We are pursuing the question of where the student goes wrong. Rabinowicz's answer is that his choices imply he has cyclic preferences, and he goes wrong because cyclic preferences are impermissible. But now it turns out that cyclic preferences are impermissible just because they can lead to a bad outcome of this sort. So 
we have not found a real explanation of where the student goes wrong. True, we have learned that his problem belongs to a recognized set of problems. But for a real explanation, we need an independent explanation of why cyclic preferences are impermissible. This money-pump explanation is incomplete.

Rabinowicz (2012: 152) does offer an independent explanation. It works by treating a person's preference between two things as a relation between the person's favoring attitudes toward the two individual things. For the person to prefer $\mathrm{X}$ to $\mathrm{Y}$ is for her favoring of $\mathrm{X}$ to be greater than her favoring of $\mathrm{Y}$. The greater than relation is necessarily acyclic. Therefore, preferences understood this way are necessarily acyclic. It follows that permissible preferences are necessarily acyclic.

However, because it implies that the student's preferences are necessarily acyclic, this explanation takes us off course in solving his puzzle. The student prefers $\mathrm{B}_{3}$ to $\mathrm{B}_{4}$; this is what makes it better. Because his preferences are necessarily acyclic, he, therefore, cannot prefer $\mathrm{A}$ to $\mathrm{B}_{3}$ and also $\mathrm{B}_{4}$ to $\mathrm{A}$. Yet he chooses $\mathrm{A}_{\text {over }} \mathrm{B}_{3}$ and $\mathrm{B}_{4}$ over $\mathrm{A}$. How come? One possibility is that his choices are not in accordance with his preferences, which is to say not in accordance with his favorings. This is certainly a way to explain how he goes wrong, but it is not the sort of explanation we need. If, in making a choice, you choose the option you favor less, that must be some sort of accident. We need a better explanation of the student's puzzle than to say he chooses wrongly by accident. We can presume the student is careful and deliberate in his choices.

The only alternative is to suppose he changes his preference between one day and the next. ${ }^{5}$ That is to say, he changes his favorings. If we are to conclude he goes wrong in some way, we shall have to say that this change of mind is impermissible. This is a matter of the persistence of an attitude. I considered the persistence of an intention in Section 6, and I take the same view about the persistence of a preference. Firstly, attitudes including preference have a causal tendency to persist, and this gives the student some causal protection against the bad outcome. Furthermore, it is not generally rational to change a preference without thinking about it, so there is some rational protection against the bad result. But both the causal protection and the rational protection are very weak: the student might rationally reconsider his preference and change it. We therefore cannot conclude that his change of mind is impermissible. This alternative, then, takes us back to something like my own first solution, which is weak. The student may do nothing wrong.

The bottom line is that it seems the student may do nothing wrong even though he arrives at a bad outcome. However, there might yet be a different explanation of why permissible preferences are acyclic. If so, this third solution might show that the student does indeed do something wrong. 


\section{Soft Incommensurateness: The Best Solution}

We have been assuming that the student faces hard incommensurateness. On that assumption, we have not been able to conclude that the student necessarily does something wrong, even though he arrives as a bad outcome.

The underlying reason for this failure is that hard incommensurateness does not provide any grading of betterness. So far as their betterness relative to $A$ is concerned, $B_{3}$ and $B_{4}$ have exactly the same standing, even though $\mathrm{B}_{3}$ is better than $\mathrm{B}_{4}$. The choice between $\mathrm{B}_{3}$ and $\mathrm{A}$ is entirely neutral, there is no normative inclination either way. The same is true of the choice between $\mathrm{B}_{4}$ and $\mathrm{A}$. There is no more normative inclination toward A in the second choice than in the first. The result is that the two choices may go in the way that leads to the bad outcome. But intuitively, there ought to be more normative inclination in the second choice because $\mathrm{B}_{4}$ is worse than $\mathrm{B}_{3}$.

Soft incommensurateness - vagueness - provides this greater inclination because it grades betterness. So now I turn to soft incommensurateness. Suppose now that there is no hard incommensurateness between $\mathrm{A}$ and the range of options $B . B_{3}$ and $B_{4}$ are in a zone of vagueness rather than hard incommensurateness. Then, although neither of them is definitely better than $\mathrm{A}$ or definitely worse than $\mathrm{A}, \mathrm{B}_{3}$ is more better than $\mathrm{A}$ or less worse than $\mathrm{A}_{\text {than }} \mathrm{B}_{4}$ is.

With vagueness, we have degrees of permissibility. If the student has a choice between $A$ and some version of $B$ within the incommensurate zone, it is not definitely permissible for the student to choose either. Moreover, the better is B within this zone, the more permissible it is for the student to choose $\mathrm{B}$, and the less permissible it is for him to choose A. So the student should in some way be more inclined to choose $\mathrm{A}_{\text {over }} \mathrm{B}_{4}$ than he is to choose $\mathrm{A}_{\text {over }} \mathrm{B}_{3}$. This is as it intuitively should be.

For more detail, remember that there are actually two zones of vagueness: the vagueness of better than $A$ and the vagueness of worse than $A$. If the vagueness is matching, as I defined it in Section 2, then either choice within the incommensurate zone is only borderline permissible. Neither is definitely permissible. Where the vagueness is overlapping, either choice within the overlap is borderline permissible. Outside the overlap, one choice or the other is definitely permissible, but for no option in the range $\mathrm{B}$, it is definitely permissible to choose $\mathrm{A}$ and definitely permissible to choose B. So there is subtlety in the permissibility of the student's choices.

Moreover, supervaluation applied to vague betterness provides a clear explanation of why the student goes wrong when he makes the choices I described. My minimal assumption about the connection between betterness and normativity tells us the student ought not to choose an option over a better one. According to every sharpening of the betterness 
relation, either $\mathrm{B}_{3}$ is better than $\mathrm{A}$ or else $\mathrm{A}$ is better than $\mathrm{B}_{4}$. So according to every sharpening, either the student ought not to choose $\mathrm{A}_{\text {over }} \mathrm{B}_{3}$ or else he ought not to choose $\mathrm{B}_{4}$ over $\mathrm{A}$. (This is a disjunction of oughts; it is not an ought governing a disjunction.) By supervaluation, therefore, definitely, either he ought not to choose $\mathrm{A}_{\text {over }} \mathrm{B}_{3}$ or else he ought not to choose $\mathrm{B}_{4}$ over $\mathrm{A}$. He does both, so one of the choices he makes is impermissible. That is why he goes wrong. In this way, we can clearly conclude that the student necessarily does something wrong.

You might ask which of his two decisions is the impermissible one, but you will normally receive no answer to that question. It is well-known (see Fine, 1975) that supervaluation can imply that a disjunction is definitely true without either of the disjuncts being so. However, because permissibility is graded, the impermissibility can be distributed between the two choices. Neither is definitely impermissible, but one may be less permissible than the other.

You might also ask what is the normative position after the student makes his first choice of $\mathrm{A}_{\text {over }} \mathrm{B}_{3}$. If he then chooses $\mathrm{B}_{4}$ over $\mathrm{A}$, he will definitely have done something impermissible. He will have acted impermissibly, either in his first choice or in his second. Can we, therefore, conclude that he ought not to choose $\mathrm{B}_{4}$ over $\mathrm{A}$ since doing so will ensure that he does something he ought not to do? No, we cannot.

An argument could be deployed to say we can. Here is one argument made by Luke Elson (unpublished). Elson starts from the premise that the student ought either not choose $\mathrm{A}_{\text {over }} \mathrm{B}_{3}$ or not choose $\mathrm{B}_{4}$ over $\mathrm{A}$. This is not the premise I have already stated. It is a wide-scope ought governing a disjunction. It does not follow from my minimal assumption about the connection between betterness and normativity. But it nevertheless seems plausible, and I shall accept it for the sake of argument. It may be reformulated to say that the student ought, if he chooses $\mathrm{A}_{\text {over }} \mathrm{B}_{3}$, not to choose $\mathrm{B}_{4}$ over $\mathrm{A}$, where the clause "if he chooses $\mathrm{A}$ over $\mathrm{B}_{3}$ " is within the scope of "ought." This formulation is arrived at by substituting logical equivalents with the scope of "ought" - a rule of deontic logic that is hard to reject (see Broome, 2013: 122).

Now suppose the student chooses $\mathrm{A}_{\text {over }} \mathrm{B}_{3}$ and his choice is irrevocable. This choice is then necessary in a temporal sense; it cannot be altered. Another rule of deontic logic that is hard to reject is "necessary detachment" as I call it (Broome, 2013: 123-125). It says that from "ought if $\mathrm{X}$ then $\mathrm{Y}$ " and "necessarily X," it follows that "ought Y." So it seems we can detach the conclusion that the student ought not to choose $\mathrm{B}_{4}$ over A. That is Elson's conclusion.

But this argument has a problem. Elson assumes that the premise remains true even after the student has made his first choice, but normative truths can alter with the circumstances. This premise is true so long as the student's first choice is open, but once that choice is made and irrevocable, it may no longer be true. 
Think about this case. For a moment, drop the assumption that $\mathrm{B}_{3}$ and $\mathrm{B}_{4}$ are in the incommensurate zone. Assume instead that they are both definitely better than $A$, though $B_{3}$ remains better than $B_{4}$. Presumably, if it is true in the original case that the student ought either not choose $\mathrm{A}$ over $\mathrm{B}_{3}$ or not choose $\mathrm{B}_{4}$ over $\mathrm{A}$, it is true in this case too. There is no reason why it should not be. Now suppose the student irrevocably chooses A over $B_{3}$, which he ought not to do. Can we conclude by necessary detachment that he ought not to choose $\mathrm{B}_{4}$ over $\mathrm{A}$ ? Of course not. $\mathrm{B}_{4}$ is definitely better than $\mathrm{A}$ and it is definitely not the case that he ought not to choose it. Indeed he ought to choose it. He went wrong in his first choice, and he ought to correct it as well as he can. Necessary detachment is hard to reject, so this example shows that the premise is no longer true once the student has made a choice. We cannot assume the premise remains true once a choice has been made. Because Elson's argument makes this assumption, it is invalid.

Revert now to the case where both $\mathrm{B}_{3}$ and $\mathrm{B}_{4}$ are in the incommensurate zone and let us look at the student's situation in more detail. Suppose for the sake of argument that $\mathrm{B}_{3}$ is near the top of this zone. Then, when the student faces his first choice between $A$ and $B_{3}$, it is not definitely permissible for him to choose A. It is borderline impermissible; indeed it may be close to being definitely impermissible. We are assuming that, all the same, the student chooses A. When he comes the next day to choose between $\mathrm{A}_{\text {and }} \mathrm{B}_{4}$, he may regret his previous choice of staying in France. He may think of choosing $\mathrm{B}_{4}$ - leaving for Britain - as a way to reverse the choice he now regrets, albeit at a cost. When he makes the second choice of $\mathrm{B}_{4}$, he ends up having done something impermissible, but the impermissibility may be located largely in his previous choice rather than his second one. By the time he comes to his second choice, he can do nothing about the previous one.

Intuitively, this way of thinking and choosing seems perfectly permissible. I find it intuitively incorrect to conclude that, once the student has chosen $\mathrm{A}_{\text {over }} \mathrm{B}_{3}$, he ought not to choose $\mathrm{B}_{4}$ over $\mathrm{A}$. When you are facing a difficult choice between incommensurate alternatives, the fact that you have previously made a particular choice does not necessarily place a normative constraint on what you should choose this time.

In sum, I think that the implication of soft incommensurateness for the puzzle of the student is exactly right. Here, soft incommensurateness gives a better account of normativity than hard incommensurateness does.

\section{Conclusion}

Soft incommensurateness supplies a better account of the puzzle of the student than hard incommensurateness does. I know of no normative phenomenon that hard incommensurateness can explain better than 
soft incommensurateness. For betterness at least, we should give up on hard incommensurateness, and recognize that incommensurateness is vagueness.

\section{Notes}

$1 \mathrm{I}$ am very grateful to Luke Elson for his comments on this chapter, and for a conversation on these topics that has continued for several years. In particular, this chapter has been influenced by his "Unsharpness and forbidden compound actions". I have also received extremely valuable comments from Ruth Chang, Wlodek Rabinowicz, Henrik Andersson, and Anders Herlitz, which have saved me from significant mistakes. Research for this chapter was supported by ARC Discovery Grant DP180100355.

2 Elson (2014). Although he rejects the collapsing principle, Elson nevertheless agrees with my conclusion in this chapter that incommensurateness is vagueness. See Elson (2017).

3 Johan Gustafsson (2018: 289) apparently assumes Elson has no good answer to this question. He therefore denies the validity of Elson's counterexample to the collapsing principle. He misses the argument from supervaluation that follows.

4 Here I agree with Carlson (2013: 456-457). Andersson and Herlitz (2018: 331-332) take the opposite view, but I think their argument is mistaken.

5 Thanks here to Luke Elson.

\section{References}

Andersson, H. and Herlitz, A. (2018), 'A more plausible collapsing principle', Theoria 84: 325-336.

Broome, J. (2001), 'Are Intentions Reasons? And How Should We Cope with Incommensurable Values?', in C. Morris and A. Ripstein (eds), Practical Rationality and Preference: Essays for David Gauthier (Cambridge University Press) 98-120.

Broome, J. (1998), 'Is Incommensurability Vagueness?', in R. Chang (ed.), Incommensurability, Incomparability, and Practical Reason (Harvard University Press), 67-89. Reprinted in Broome, J. (1999), Ethics Out of Economics, (Cambridge University Press).

Broome, J. (2013), Rationality Through Reasoning (Wiley-Blackwell).

Carlson, E. (2004), 'Broome's Argument against Value Incomparability', Utilitas 16: 220-224.

Carlson, E. (2013), 'Vagueness, Incomparability, and the Collapsing Principle', Ethical Theory and Moral Practice 16: 449-463.

Chang, R, (2013), 'Commitments, Reasons, and the Will', Oxford Studies in Metaethics 8: 74-113.

Chang, R. (2017), 'Hard Choices', Journal of the American Philosophical Association 92: 586-620.

Chang, R. (1998), 'Introduction', in R. Chang (ed.), Incommensurability, Incomparability and Practical Reason (Harvard University Press) 1-34.

Chang, R. (2021), 'What Is It to Be a Rational Agent?', in R. Chang and K. Sylvan (eds), The Routledge Handbook of Practical Reason (Routledge). 
Elson, L. (2014), 'Borderline Cases and the Collapsing Principle', Utilitas 26: 51-60.

Elson, L. (2017), 'Incommensurability as Vagueness: A Burden-Shifting Argument', Theoria 83: 341-363.

Elson, L. (unpublished), 'Unsharpness and Forbidden Compound Actions'.

Fine, K. (1975), 'Vagueness, Truth and Logic', Synthese 30: 265-300.

Gustafsson, J. and Rabinowicz, W. (2020), 'A Simpler, More Compelling Money Pump with Foresight', Journal of Philosophy 117: 578-589.

Gustafsson, J. (2018), 'Does the Collapsing Principle Rule Out Borderline Cases?', Utilitas 30: 483-492.

Rabinowicz, W. (2012), 'Value Relations Revisited', Economics and Philosophy 28: 133-164.

Sartre, J.P. (2007), Existentialism is a Humanism (Yale University Press), (originally 1946). 